$L A--9374-1.5 S$

DE82 019188

\title{
Radially Resolved Emission Spectroscopy on ZT-40M
}

\author{
R. G. Watt
}

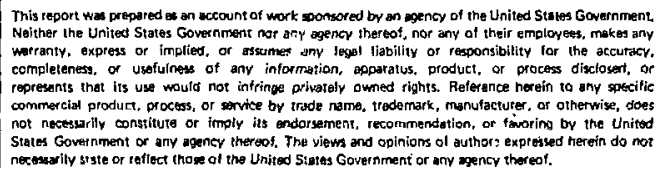

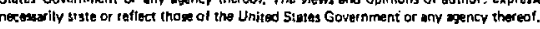


RADIALLY RESOLVED EMISSION SPECTROSCOPY ON ZT-40M

by

R. G. Watt

\section{ABSTRACT}

Measurements of line integrated emission profiles of $D_{B}$, OIII, OV, $O V I$, and $C V$ line radiation have been performed in the ZT-40M device at Los Alamos National Labocatory. The behavior of these emission profiles will be presented for several operating currents, f111 pressures, and current risetimes. The basic oxygen radial structures are seen to resemble an onion skin at any particular time, with OIII farthest out in radius and OVI nearest the axis, as one would expect in the absence of any anomalous heating mechanisms (such as thermal instabilities). The rate at which the various 11 nes occur during several different current level discharges appears to be consistent with Increased losses for Increased $\dot{\mathrm{I}}_{\phi}$ during the early phases of heating (up to OVI), while the later stages are consistent with a much lower energy loss and a heating rate proportional to $\dot{\mathrm{I}}^{2}$. Evidence of enhanced wall interaction in the latter stages of the discharge is presented.

\section{INTRODUCTION}

Radially resolved emission spectroscopy studies have been carrled out in the 2T-40M reversed-field-pinch ${ }^{1}$ device at Los Alamos National Laboratory. Studies of the radial structure of 1 ines of various lonization potentials as a function of time help one to understand the evolution of the plasma discharge In a global sense. In particular, such studies ald one in determining the macroscopic differences between good and poor discharges [an example might be a lack of $\mathrm{CV}(227.1 \mathrm{~nm})$ radiation from a cold discharge, or a constant decrease in CV radiation intensity as the discharge vessel gets conditioned over many shots]. 
The multichord spectrometer system (MCSS) used for these studies has been described elsewhere. ${ }^{2}$ The six-chord system has a wavelength resolution of $\sim 0.4 \mathrm{~nm}$ and a chord-to-chord intensity calibration uncertainty of $10 \%$. The chords have Impact paraweters from $-4 \mathrm{~cm}$ to $+16 \mathrm{~cm}$ wh respect to the vacuum vessel minor axis with a chord-to-chord separation of $\sim 4 \mathrm{~cm}$. In all discussions in this report, impact parameters w111 be measured from the center of the discharge vessel. The chord-to-chord calibration uncertainty results In a combined uncertainty from the axis to outer chord of $\sim 25 \%$, which makes some measurements relatively uncertain (1n particular, measurements of the integrated background radiation that is quite uniform in impact parameter). In cases where total differences across the profile are no more than $25 \%$, as In the case of most lines after burnthrough, detalled knowledge of the radial structure must be 1 intted by this resolution. This limiting resolution also makes any detalled unfolding of radial structure (after the line begins to burn through) from the line integral measured data via Abel inversion quite prone to error. Such analysis has been done, particularly for the carbon data (at early times), but because of the inherent uncertainties in the process, no such results will be discussed here.

Before presentation of detalled data, it 18 worth noting that the vacuum vessel shows evidence, both spectroscoplcally and from Thomson scattering temperature measurements, ${ }^{3}$ of a long-term conditioning process. The results presented here show that process in a pronounced manner through the CV amplitude. After 2000 shots and with no vacuum opening in the previous 600 shots, the carbon radiation level wes down approximately a factor of 4 from results early in the 11 fe of $\mathrm{ZT}-40 \mathrm{M}$, with the result that the background under the line in the spectrometer acceptance window $(0.4 \mathrm{~nm}$ FWHM) was within a factor of 2-3 of the peak intensity of the 11ne. After opening the vacuum vessel and installation of ceramic sleeves for the multipoint Thomson scattering system, " the CV radiation level was once again at the high levels seen early in the discharge vessel history. Profiles from each period will be used where appropriate.

The presentation in this report will be broken into three major areas: (1) overall data for standard reversed-field operation at a current risetine of 0.25 as and current levels from $120-250 \mathrm{kA}$, (2) results of a study conducted to analyze the effects of the risetime of the toroldal plasma current, and (3) some comnents on behavior of radiation in the same wavelength 
region as the CV line late in a discharge ( $>3 \mathrm{mb}$ ) that is belleved to be attributable to a series of unresolvable low-lying metal 11 nes that may be indicative of strong wall interaction.

Because of the intimate connection between line emission and the local electron density ( $I \propto n_{e} n_{i}$ ), it is useful to have a line integral density profile $e^{5}$ under the conditions used for most discharges to help interpret radial intensity profiles. Figures 1 and 2 are a single set of density profiles for a standard 180-kA flattop current shot (\#6949) shown on both a short and long time scale for this comparison. Lower current discharges have simllar spatial behavior.

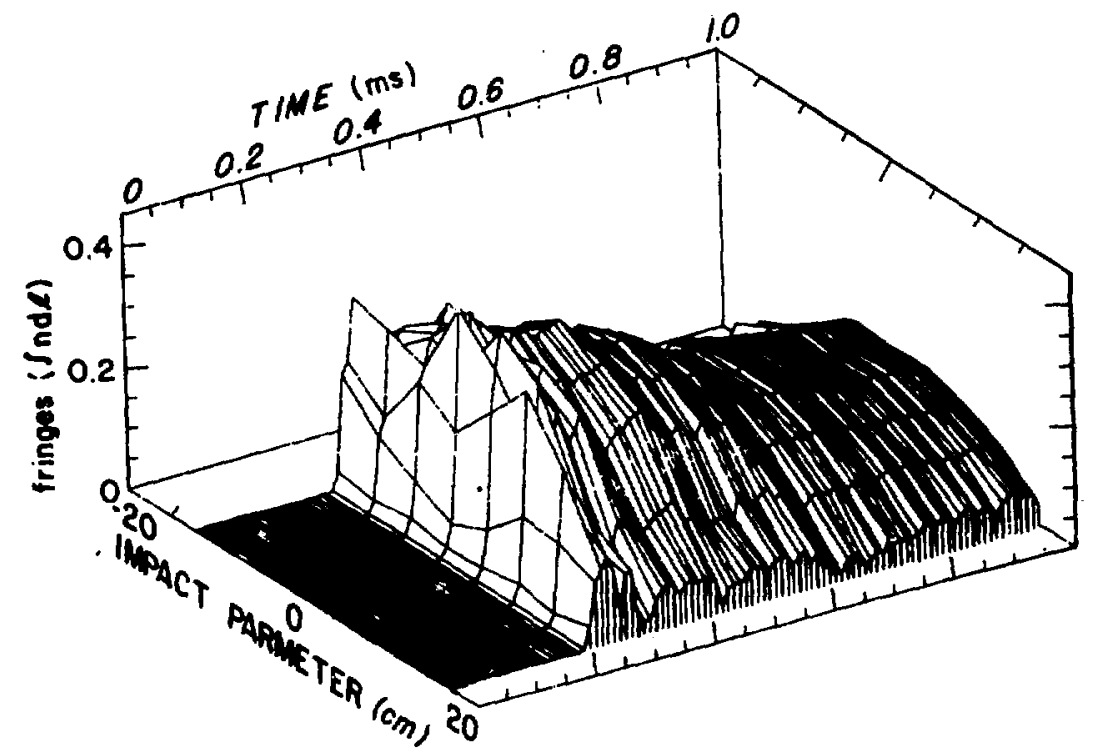

Fig. 1 .

Line integral density, profile history for a typical 190-kA reversed-field pinch discharge showing the formation phase $(0-1 \mathrm{~ms})$ of the pinch. 


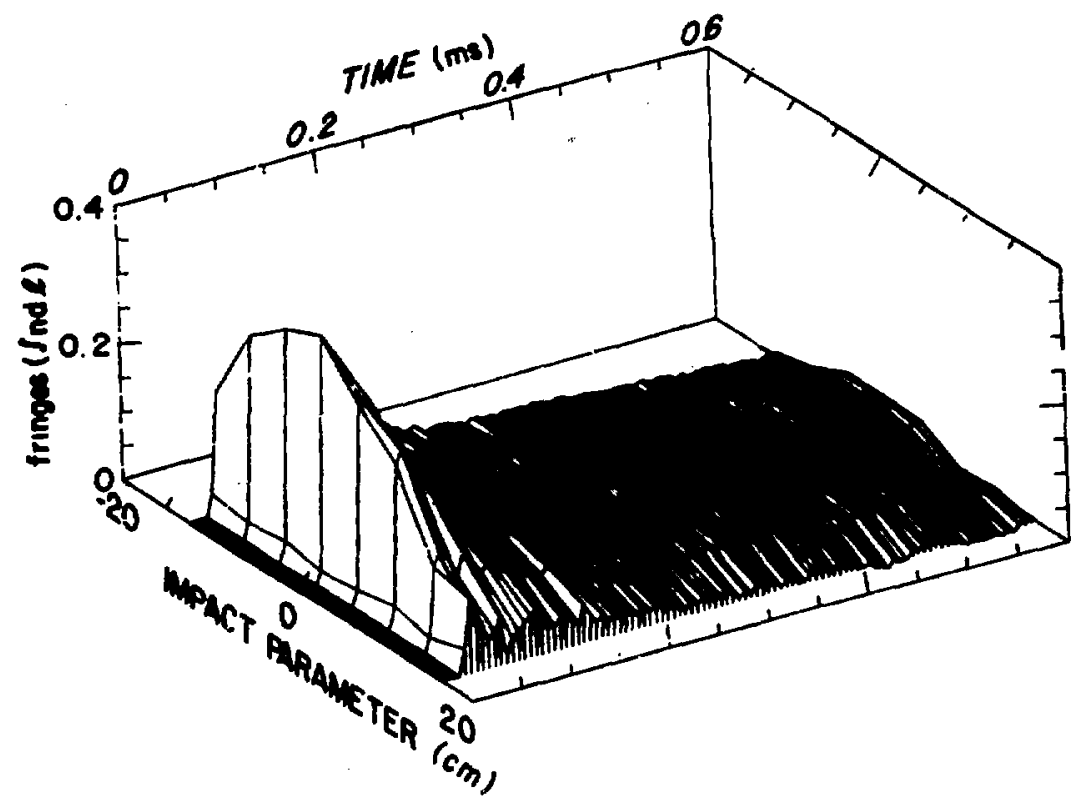

Fig. 2.

Profile history of Fig. 1 on a longer tine scale.

II. COYPOSITE DATA PLOFILES FOR STANDARD OPERATIONAL CONDITIONS

2T-40M normally operates as a reversed-field pinch with a current level between $120 \mathrm{kA}$ and $250 \mathrm{kA}$. Most extensive data have been taken at the 180-kA plasan current level (current inside the Inconel vacuun vesse1). Results obtalned at three current levels $(120 \mathrm{kA}, 180 \mathrm{kA}$, and $240 \mathrm{kA})$ w111 be presented and compared in this section in order of increasing current level.

A. $120 \mathrm{kA}$

Operation at this level is characterized by fill pressures of $1-5$ atorr (standard being 1.2 wtorr) and revertal depths at the wall of approximately $0.2 \mathrm{~T}$. Peak plasme current occurs at $0.5 \mathrm{~ms}$. Under the standard 1.2-ntorr f111 conditions, radial profiles have been obtained for $D_{B}(486.1 \mathrm{~nm})$, OIII $(326.1 \mathrm{~mm})$, OV $(278.1 \mathrm{~mm})$, OVI $(343.4 \mathrm{~nm})$, and $\mathrm{CV}(227.1 \mathrm{~nm})$. The carbon data used here are from the period of lowest emission levels (and presumbly cleanest conditioning), as are all other profiles.

The data presented here and in the following sections have been averaged over a number of chots and thus represent the general behavior, with any peculiarities on a given shot washed out by the averaging procesa. In particular, the arsive intensity spikes seen in many CV profiles originating 
fron the wall region are subdued. This feature will be discussed later in this report. The various line integral intensity profiles are shown for the first millisecond in Figs. 3-7 for $D_{\beta}$, OIII, OV, OVI, and CV, respectively. Clearly observed is the' fact that different lines have peak intensities at different times during the discharge. An overall compilation of the tine of peak intenaty for all current levels will be presented later.

Because comparisons of profiles for different ionization states of a given atom can provide radial ion density and temperature information, it is Informative to look at a given point in time and compare profiles. Figure 8 . is such a comparison [smoothed by eye and averaged over both time (0.5-ims window) and shots] for OIII, OV, and OVI at $0.45 \mathrm{~ms}$. It is clear, even in the absence of Abel inversion, that at this time during the discharge the OIII Is peaked near the outside, $O V$ is annular, and OVI is peaked on axis, thus constructing a conceptually consistent picture of the radiation field. Note also that the absolute intensity of the profiles has been changed to display

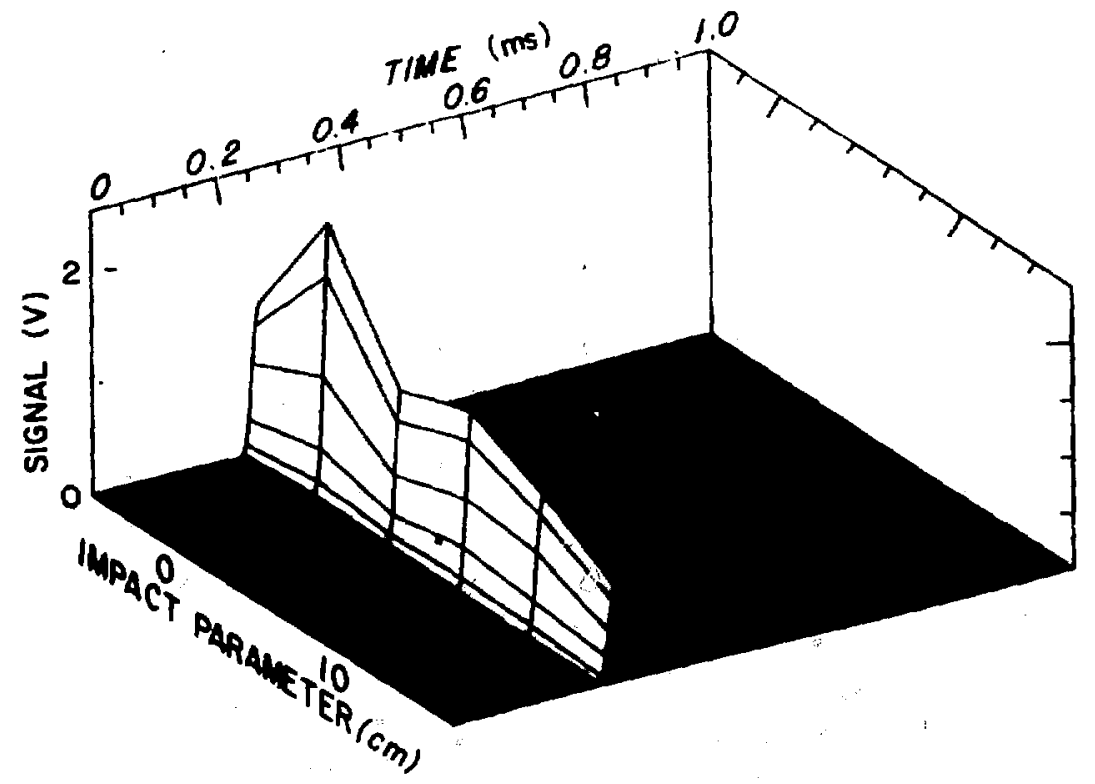

F1g. 3.

Average $D_{B}$ radiation line integral profiles at $120 \mathrm{kA}$ and 1.2 mtorr, showing the pinch formation phase. 


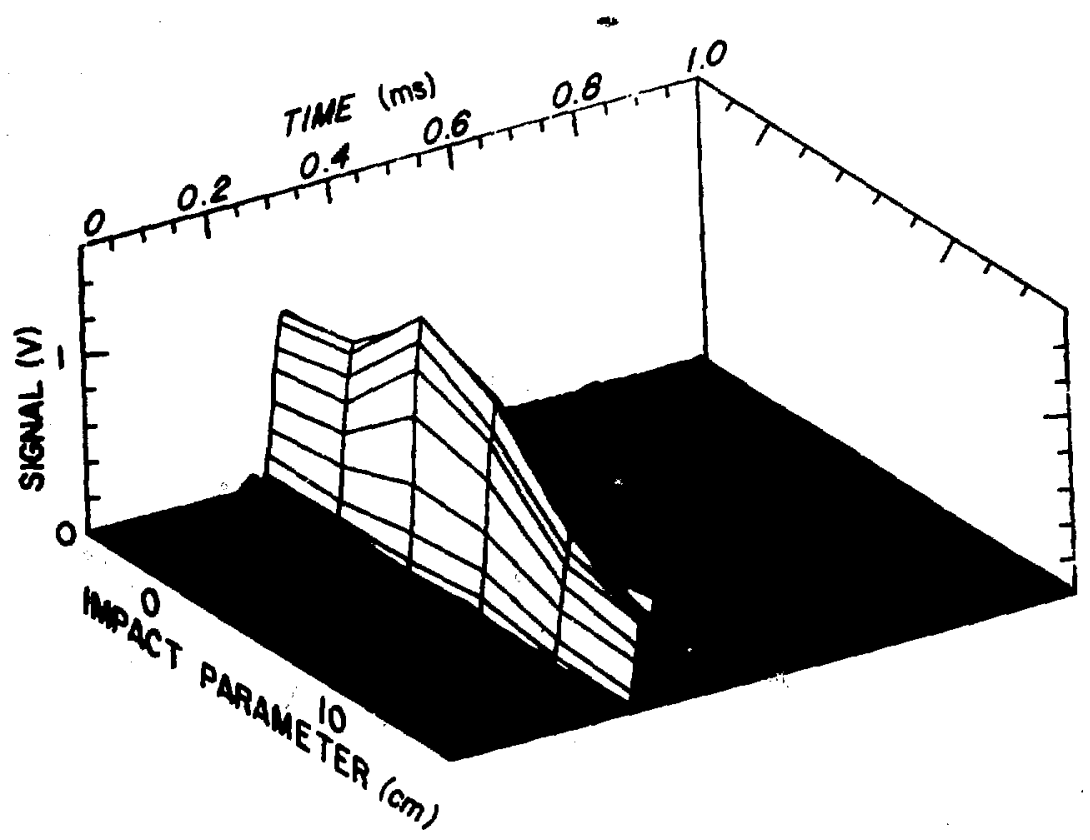

Fig. 4 .

Average OIII profiles at $120 \mathrm{kA}$ and 1.2 motor.

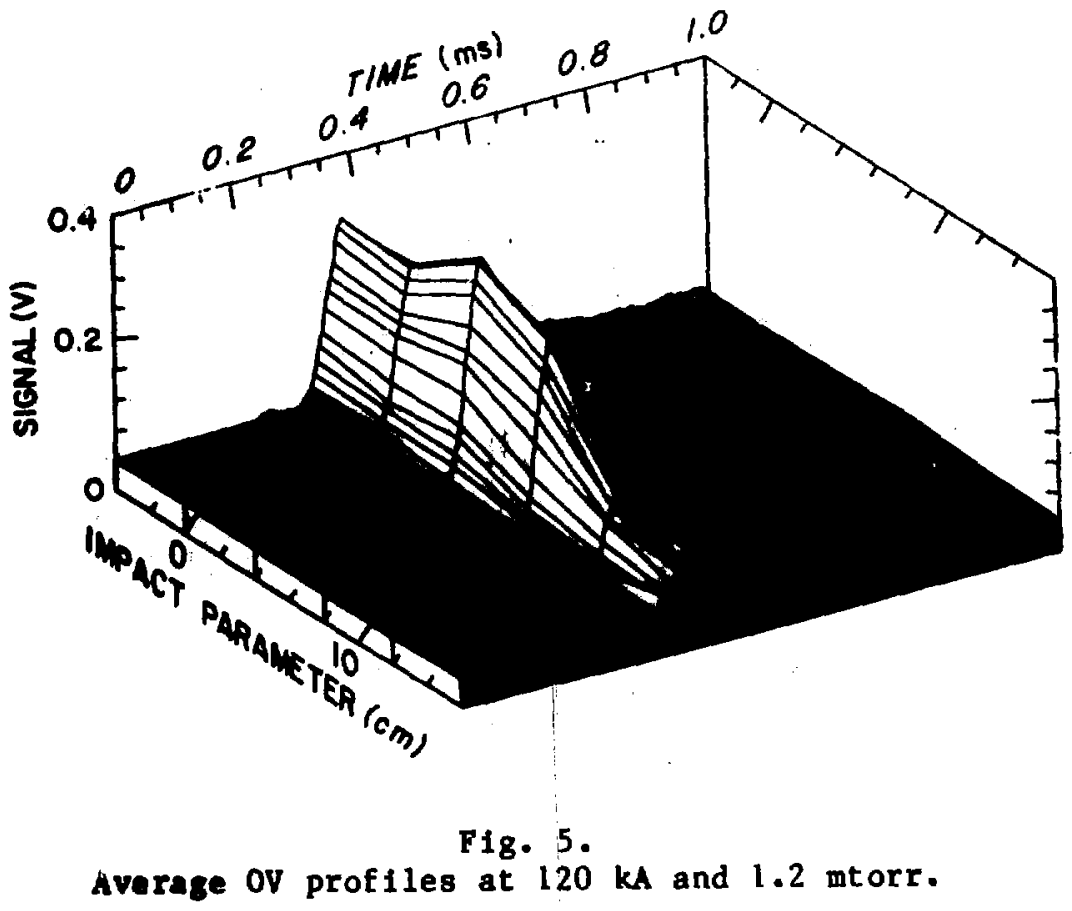

6 


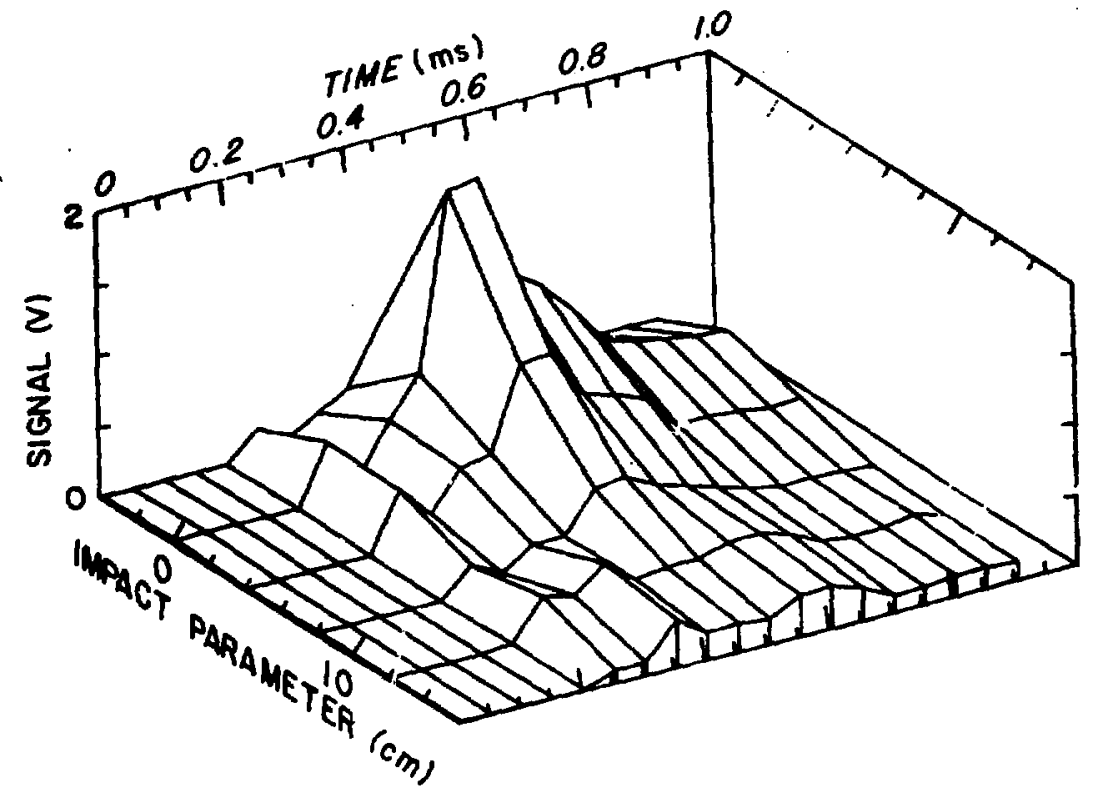

F18. 6 .

Average OVI profiles at $120 \mathrm{kA}$ and 1.2 ntorr.

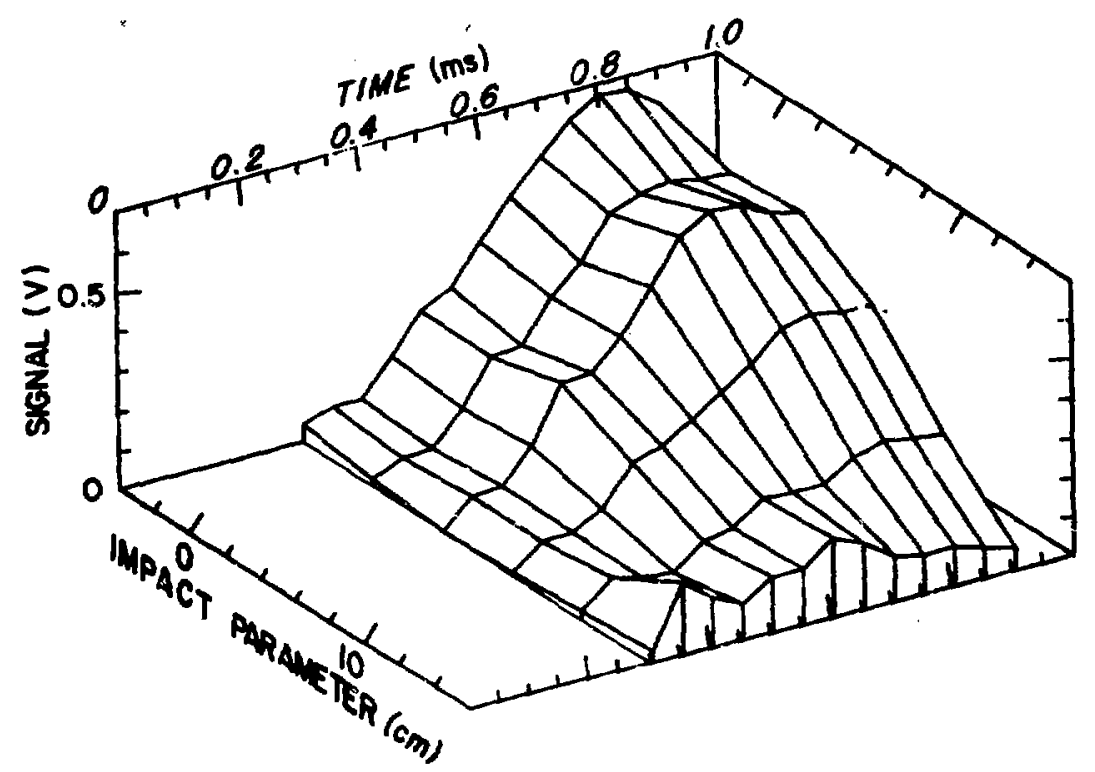

F18. 7 .

Average CV prof 11 es at $1.20 \mathrm{kA}$ and 1.2 ntorr. 


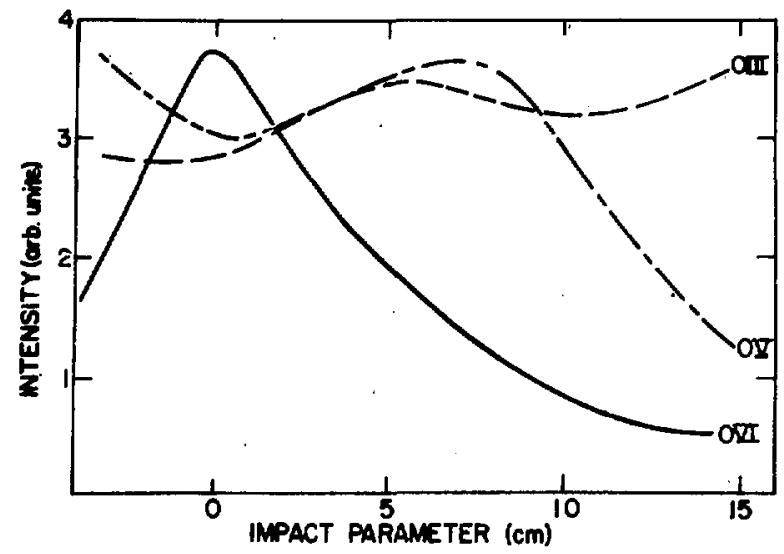

Fig. 8 .

Comparison of OIII, OV, and OVI radial profiles (11ne Integrated) at $0.45 \mathrm{~ms}$ Into the discharge ( $0.2 \mathrm{~m}$ into the plasma current), showing clear evidence of an onton skin formation. The OVI signal has been reduced to 0.2 of its original size to fit on the same plot as the OIII and OV signal.

the radial comparison clearly; the OIII and OV are really at much lower intensity than the OVI at this point during the discharge.

B. $180 \mathrm{kA}$

Operation at this level occurs for f111 pressures of $1.2-5$ ntorr, with the normal f111 being 1.6 mtorr. Field-reversal depth and time of peak current are the same as for the 120-kA case. Composite profiles under these conditions for $D_{B}, O V, O V I$, and $C V$ are shown in Figs. 9-12, respectively. The time of occurrence of the $C V$ peak has decreased markedly from the 120-kA level, Indicative of a higher heating rate, at least after the oxygen radiation has burned through. 


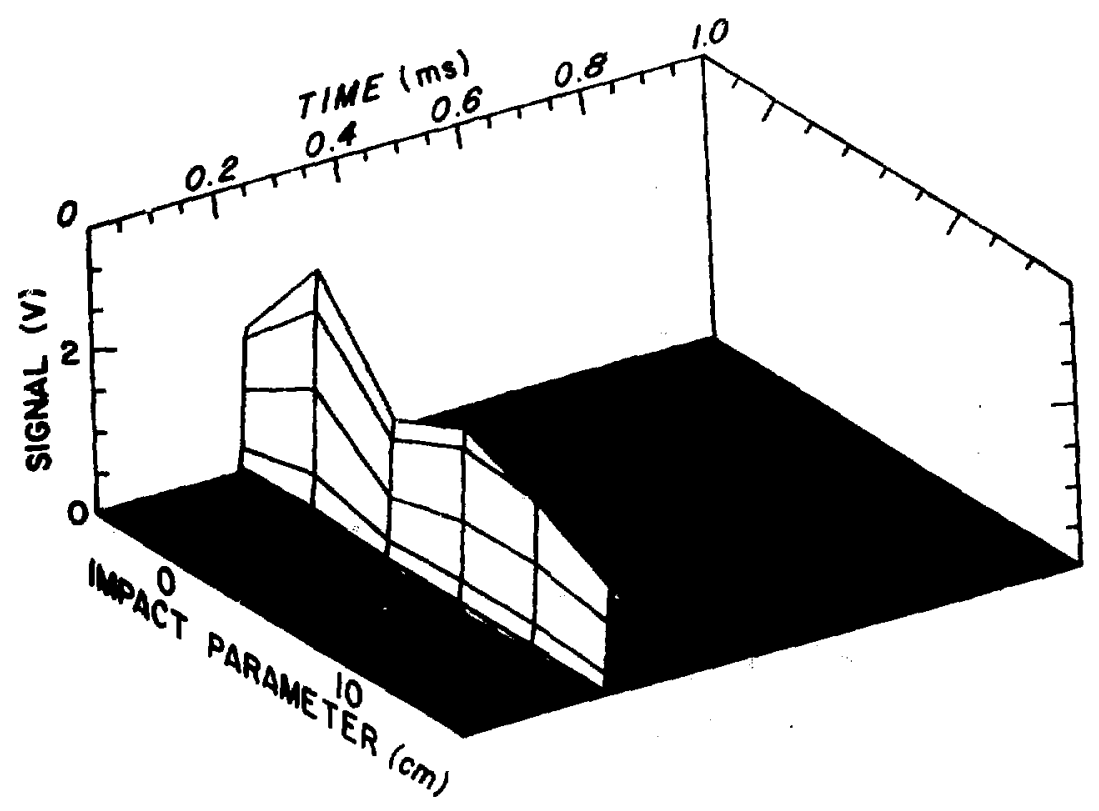

Fig. 9.

Average $D_{B}$ radiation profiles for $190 \mathrm{kA}$ and $1.6 \mathrm{mtorr}$, showing the pinch formation phase.

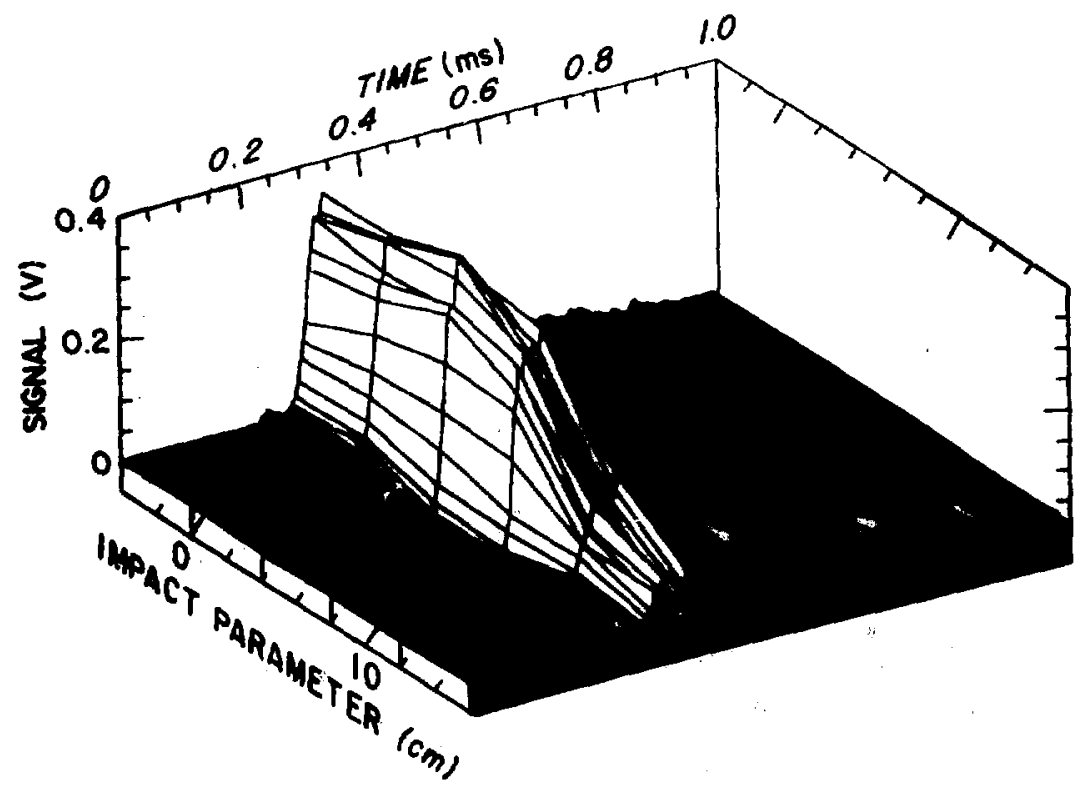

Fig. 10 .

Average OV prof $11 \mathrm{es}$ at $190 \mathrm{kA}$ and $1.6 \mathrm{mtorr}$. 


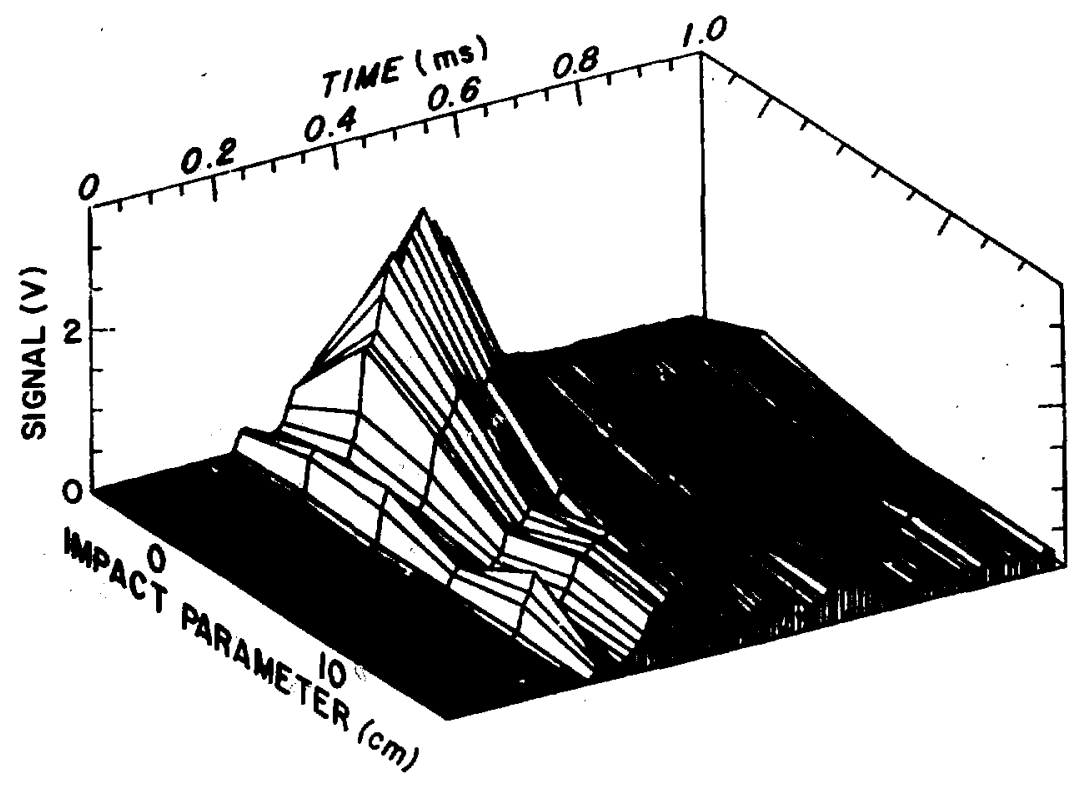

Fig. 11 .

Average OVI profiles at $190 \mathrm{kA}$ and $1.6 \mathrm{mtor}$.

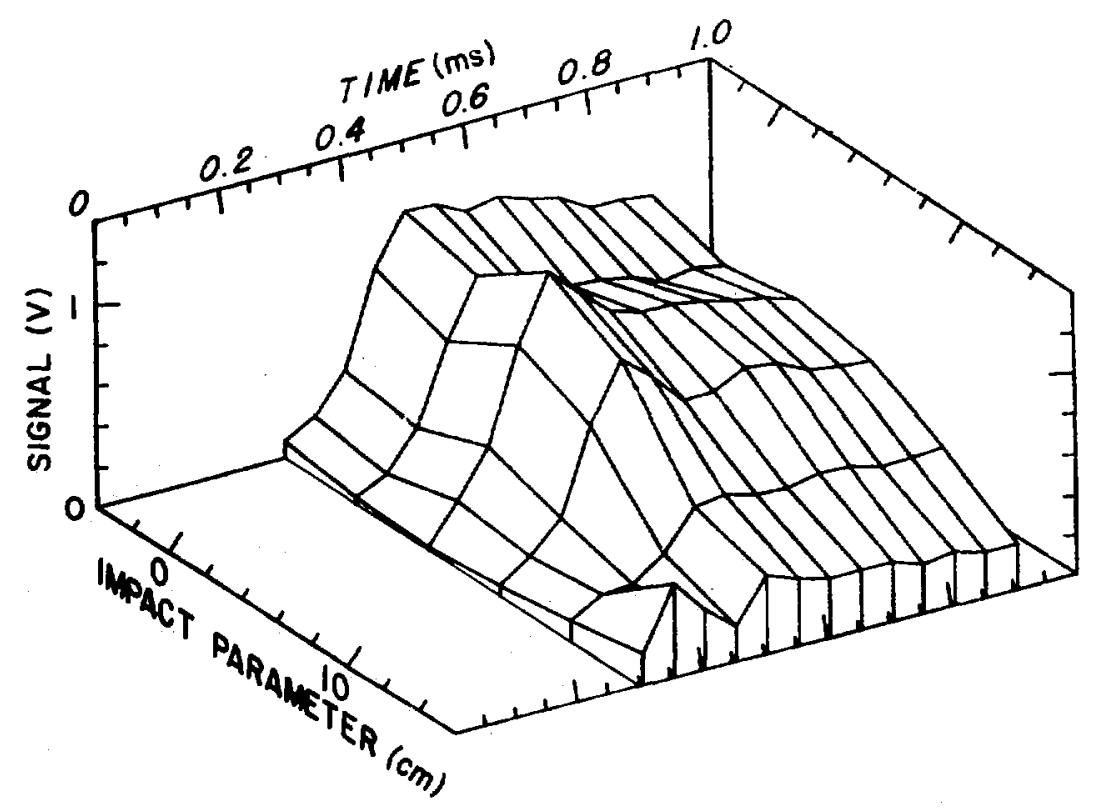

F1g. 12 .

Average $\mathrm{CV}$ profiles at $190 \mathrm{kA}$ and 1.6 mtorr. 
C. $250 \mathrm{kA}$

A linited number of discharges were taken at this level. No standard operating pressure was established. In the absence of a detalled standard data base, what is presented here is a comparison at 3-ntorr $f 111$ of the CV profiles seen at 180-kA and 240-kA plasma current (F1gs.13 and 14, respectively). Also shown for comparison are the standard 180-kA, 1.6-ntorr fill CV profiles on the same time scale (Fig. 15). The peak intensity is seen to Increase with plasma current while the time to peak decreases, again Indicative of a higher heating rate during this portion of the discharge. The apparent decrease in half-width at the peak intensity point for the 250-kA data ay reflect differences in elther temperature profiles, ton density profiles, or both, and may be intimately tled up with the detafled transport properties. Much wore work needs to be done in this area to define the physics involved.

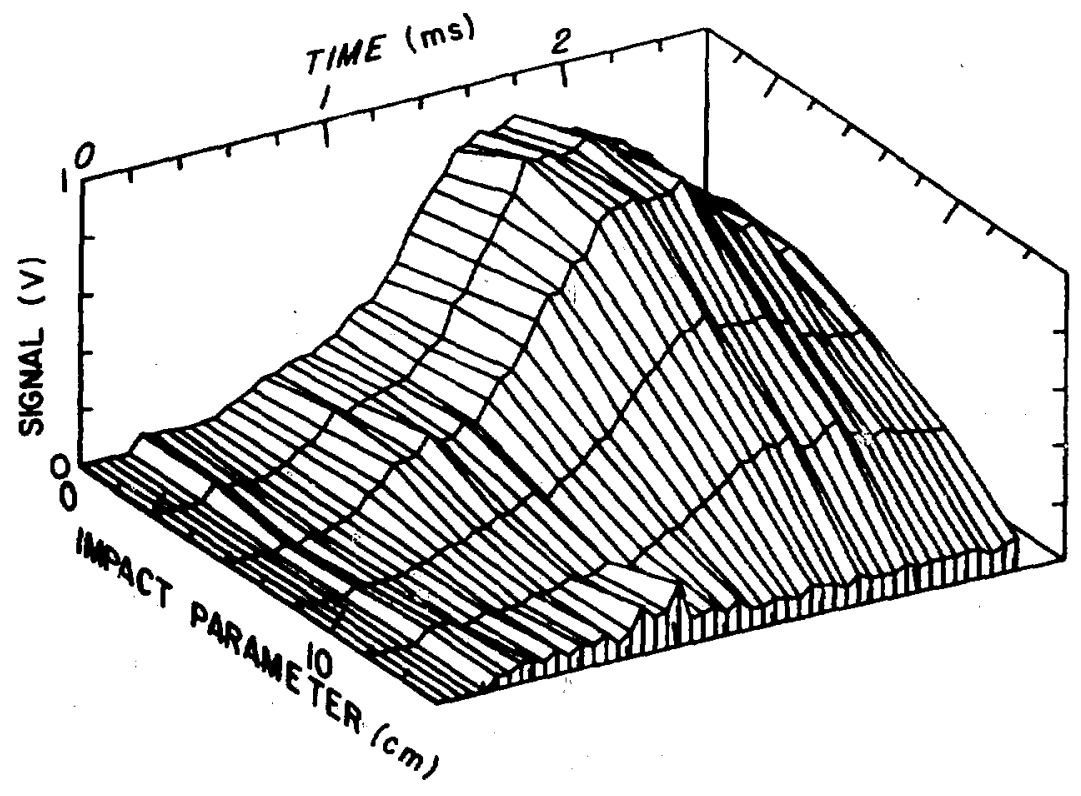

Fig. 13.

Average CV IIne integral prof 1 les at $190 \mathrm{kA}$ and 3 atorr. 


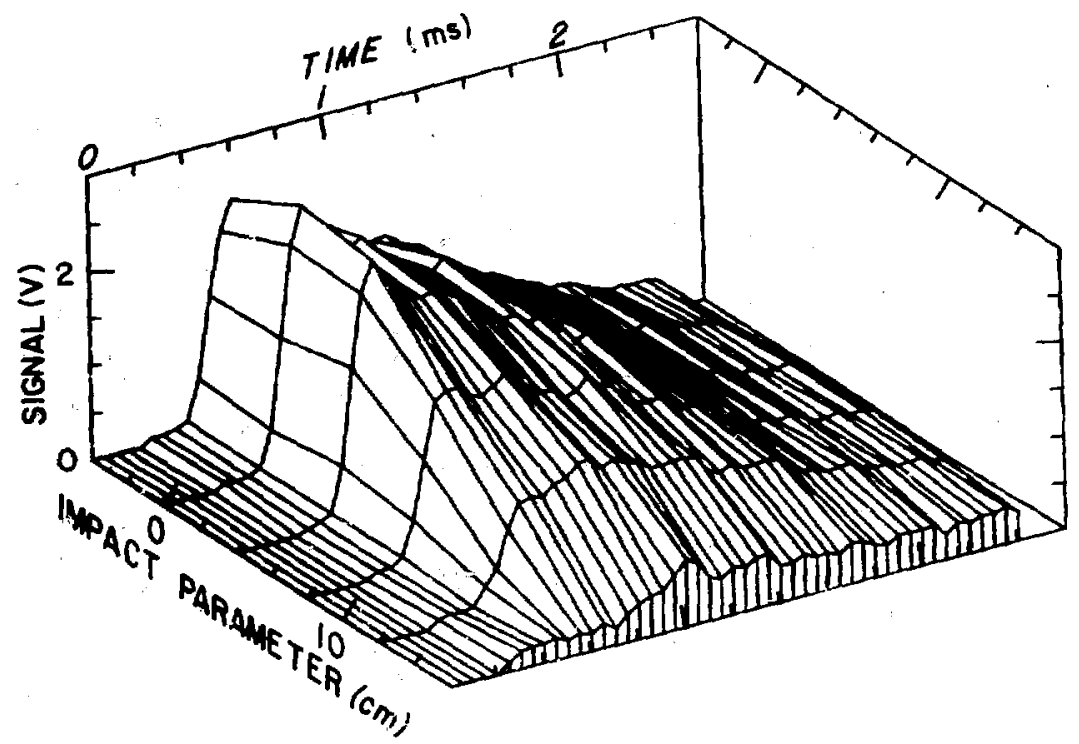

Fig. 14 .

Average CV line integral profiles at $250 \mathrm{kA}$ and 3 mtorr.

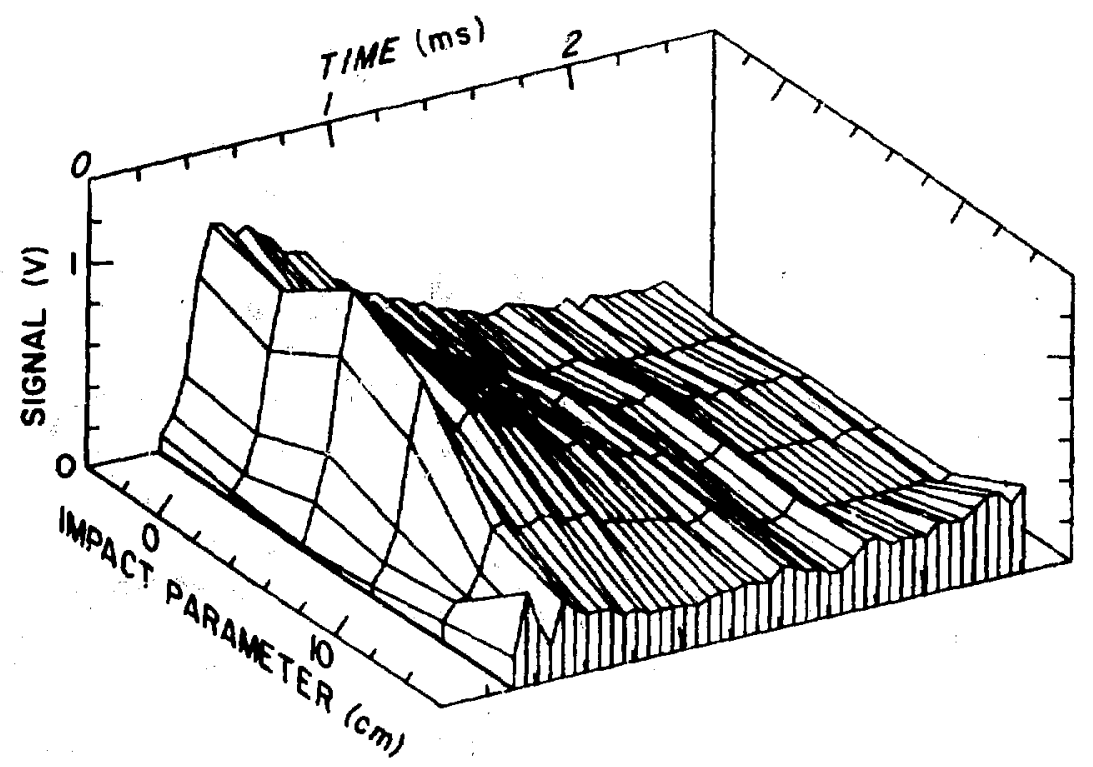

Fig. 15.

Average CV line integral profiles at $190 \mathrm{kA}$ and $1.6 \mathrm{mtorr}$ for comparison with Figs. 13 and 14 . 


\section{Ionizat 1on Energy Dependence}

The preceding data base, besides showing the radial structure of any IInes, way also be used to look at the evolution of the plasme temperature in a very approxianate anner. Because the lines peak at different times and have different Ionization potentials, we may plot the lonization potential va time to peak for vartous current levels, as shown in Fig. 16. The points for $D_{\beta}$ through OVI lie on curves that are basically the same for the separate current levele. The curves begin to deviate radically from each other after oxygen has burned out, so there are apparent1y two separate heating phases. If one assumes it takes a plasma temperature $T_{e} \approx 30 \%$ of the lonization potential of a given species to begin to burnthrough a given line (from zero-dimensional code calculations, as well as for corona equilibrium), 6 and if one assumes the same emitting volume (approximately correct up to the burnthrough time for a given line, 1.e., emission from the inner region in all cases), then very crudely, the plots of $X$ vs $\tau_{\text {peak }}$ may also be used as curves of $3 T_{e}$ vs time for early times during the discharge.

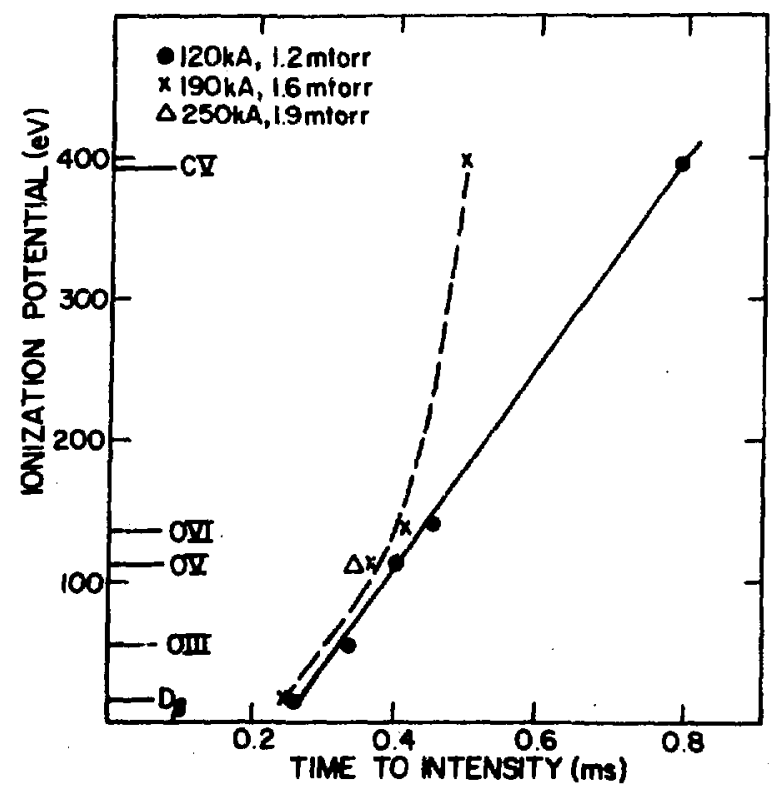

F1g. 16.

Ionization potential ve time of occurrence of the lines obeerved. This plot may be interpreted as $3 T_{e}$ vo time within the caveate discussed in the text. Current starts at $0.25 \mathrm{me}$. 
To interpret what the heating rates implied in Fig. 16 mean in terms of plasma energy input and confinement, let us consider a very crude model. Let us assume that as the plasma evolves through each heating (1onization) stage, regardless of peak current (or $\dot{I}$ ), the density, temperature, and current radial profiles evolve to a given state regardless of the tine scale to do so. We may then write the energy balance equation for the plasma energy $W_{p}$ $\left(=3 n_{e} k T_{e}\right)$ in terms of average quantities as

$$
\frac{\partial W_{p}}{\partial t}=n J^{2}-\frac{W_{p}}{\tau_{E}},
$$

where $\eta$ is the plasma resistivity at a given time, $J$ is the current density, and $\tau_{E}$ is the energy confinement time (time to l/e of the initial energy in the absence of an energy source). Viewed in terms of energy confinement early In the current rise where $J \approx j t$, ope can make two distinct statements. ( 1 ) Before OVI burnthrough $\left(T_{e}<40 \mathrm{eV}\right), \frac{{ }_{p}}{\partial t}$ is 1ndependent of $j$ (from Fig. 16, as $j^{2}$ increased by a factor of $4, \dot{w}_{p}$ only changed by at most $10 \%$ ), so the energy loss term must be comparable to the source term and $n J^{2}$ and $T_{E}^{-1}$ must both be proportional to $\mathrm{j}^{2}$ in order for the difference between source and loss to be only weakly dependent on the current rate of rise. (2) Between ovI burnthrough $(\sim 40 \mathrm{eV})$ and $\mathrm{CV}$ peak $(\sim 120 \mathrm{eV})$, the heating rate scales with $\mathrm{J}^{2}$ experimentally (Fig. 16), so the loss term during this period must be only a small fraction of the source term. No statement about the form of $\tau_{E}$ during this perlod can be made based on these data. Any such statements must come from much more detalled $T_{e}(r), n_{e}(r)$, and $J(r)$ measurements.

\section{RISETIME EFFECTS}

As mentioned earlier, a series of discharges were conducted in which the risetime of the plasma current was varied from the usual $0.25-\mathrm{ms}$ rise to peak current to values of $0.75 \mathrm{~ms}$ and $1.5 \mathrm{~ms}$. During this study the MCSS system was left tuned on the $C V(227.1 \mathrm{~nm}) 11$ ne. As mentioned earlier, the amplitude of $C V$ radiation underwent an abrupt increase at a $t$ ime that coincided with the change to 0.75 ms risetine (without vacuum opening). Because it is of Interest to see whether $\dot{I}_{\phi}$ affects the profile and because the profile was 
farther out of the background after this series, the 0.25-ns profile used here will be from discharges after the risetime study. The amplitude of the radiation does not seem to affect the tine or pressure dependence.

To quantify the various dependencies in this CV study, plots have been made showing the time to peak intensity and amplitude at peak intensity (FIgs. 17 and 18) for various f111 pressures for the three current risetines used (180-kA plasma current). As expected, the time needed to reach peak amplitude was monotonically increasing with $f 11$ pressure in all cases. Also observed was that $1 \mathrm{t}$ takes longer for CV $(227.1 \mathrm{~nm})$ to appear with a lower 'plasma (longer risetime) consistent with the post-oxygen-burnthrough result at $0.25-m s$ rise for different current levels. From the data for anplitude vs fill pressure it appears that there may be some universal curve whose peak

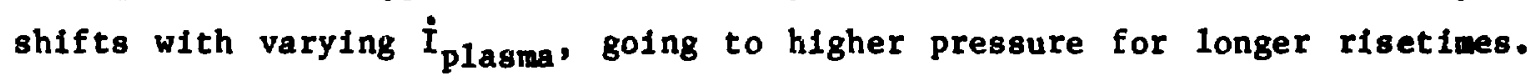
Unfortunately, the peak seems to be outside the operating window at the two extremes, with the $0.25-m 8$ risetine peak residing below the breakdown linit ( 1.0 mtorr) at $180 \mathrm{kA}$, and with the $1.5-\mathrm{ms}$ risetime peak belng at such high

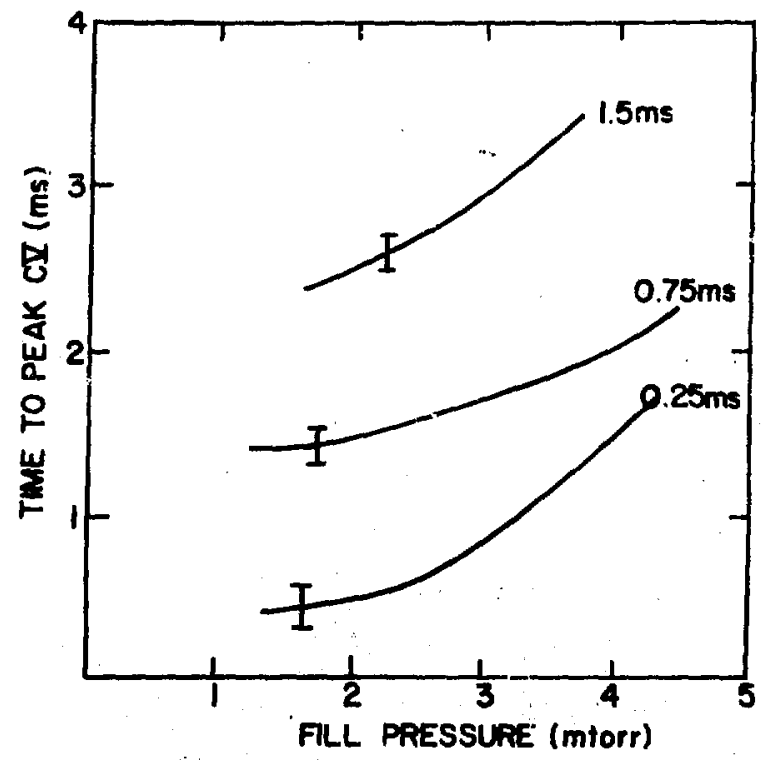

F18. 17.

Tine of occurrence of $\mathrm{CV}$ as a function of pressure for the three risetimes studied thus far. In each cabe the ebsolute tive into the current waveform is the plotted tive minue the risetime hown as abel for the curve. 


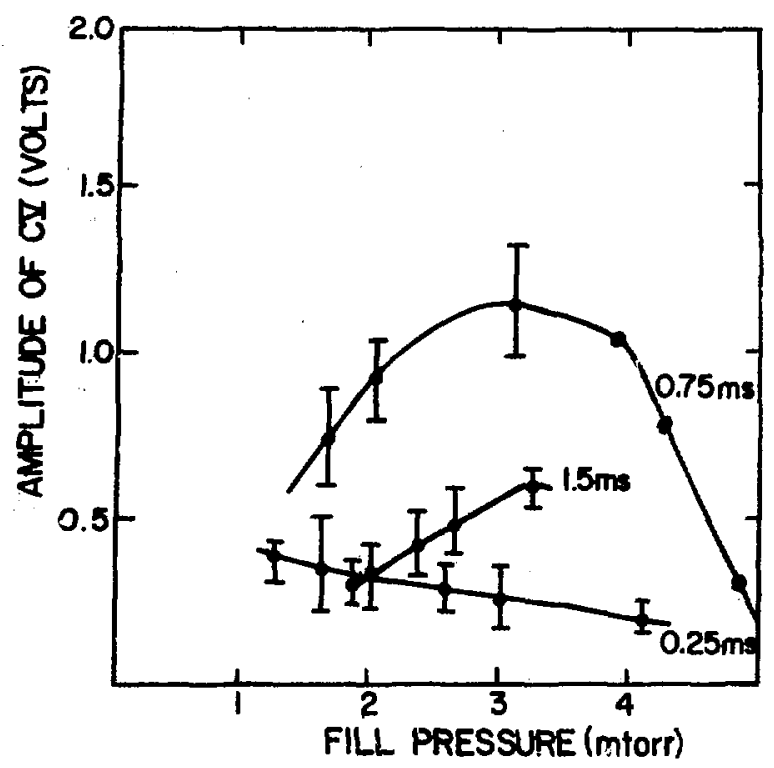

F18. 18 .

Amplitude of the peak CV signal vs fill pressure for the various risetimes shown on the curves.

pressure that the necessary conditions for the peak to occur (presumably conditions on $\mathrm{T}_{e}$ ) cannot be reached during the discharge duration. Regardless of the location of the peak, it is elear that for the range from 1-3 mtorr where most successful operation seemed to occur for these experiments, the two extremes are on opposite slopes of some curve. Combining these two plots (in effect, suppressing the pressure dependence) ylelds the set of curves shown in Fig. 19, from which it is clear that the time to peak and amplitude of the peak are intimately related, presumably by the transport process that brings the carbon 1 ons off the surface of the wall during startup.

It was necessary during these risetime experiments to vary the toroldal blas field in order to achleve reversal at a particular fill pressure (a result of a density pumpout dependence on blas field). As long as reversal was achleved, the depth of reversal did not seem to affect the tine of occurrence or level of the peak radiation. It also had little effect on the shape of the profile. For comparative purposes, a plot of the profile at the time of peak intensity is shown In F1g. 20 for each of the risetiaes. Within the accuracies of the measurement there appears to be 1ittle if any difference in the final plasma columa structure. The only thing that appears to change 


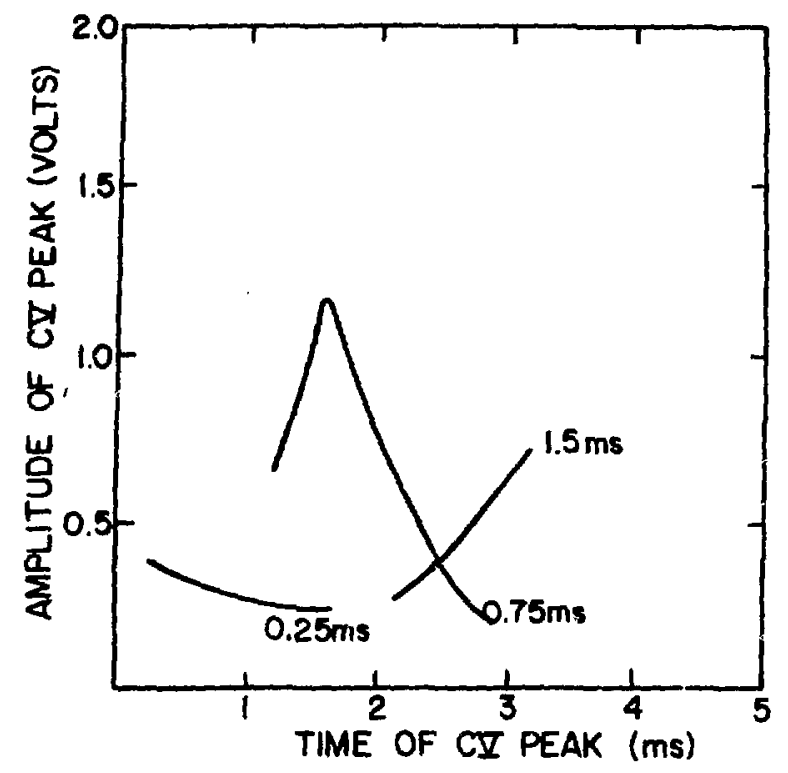

Fig. 19.

Amplitude of the peak CV signal va tiue to peak (again with the time of fset of FIg. 17) ghowing the apparent curve with changing peak nentloned in the text.

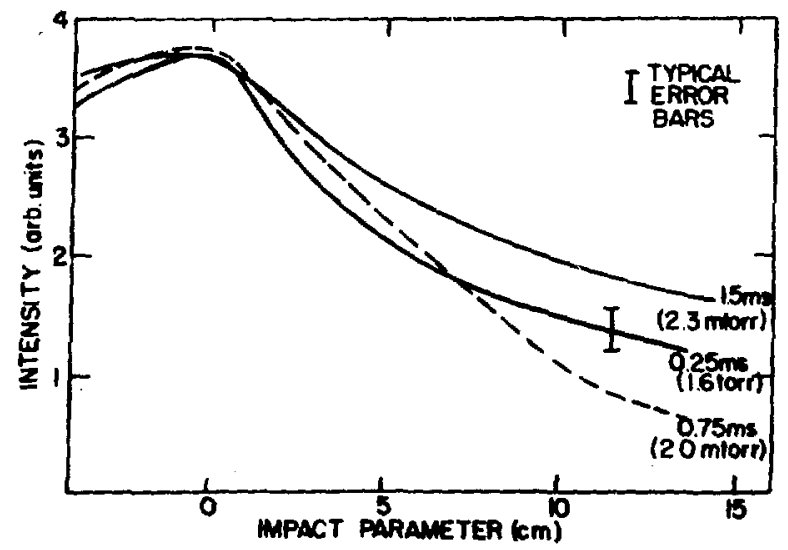

Fig. 20.

Comparison of the line integral CV profile at the time of peak intensity for the three risetises (at the fill pressure corresponding to best operation of the plasen, as noted with each curve).

with risetiwe is the length of tiwe it takes to achieve the final plasma state, at least as long as the $f 111$ pressure resides near the peak of the $\mathrm{CV}$ enieston ve $P_{0}$ curve. 


\section{WALL INTERACTION}

Throughout the life of $\mathrm{ZT}-40 \mathrm{M}$ there has been a qualitative change in the behavior of the radiation observed under the $\mathrm{CV}$ 11ne. As mentioned in the Introduction, the MCSS system has a wavelength resolution of only $\sim 0.4 \mathrm{~nm}$. Because of this, for weak 11 nes it is possible for background radiation caused by recombinetion or closely spaced adjacent lines to interfere with desired measurements. This has been the case for the CV measurements for the later discharges in the $11 \mathrm{fe}$ of $2 \mathrm{~T}-40 \mathrm{M}$.

Figure 21 is a profile history for a single shot (\$6854, smoothed over a: 100- s $_{\mathrm{s}}$ sliding square window) showing a massive increase in light in the outermost chord during the startup phase. This particular discharge was a 1.5-ms risetime, 3-mtorr discharge chosen to display what appears to be a violent wall interaction early in time. Such interactions occur on more than 507 of all discharges (regardless of risetime) during this particular historical period but were almost never observed during the earliest discharges. The cause is unknown. The radiation is uniform over \pm 2 nm. It is not observed in the vicinity of other ilines investigated (particularls $D_{\beta}$ ).

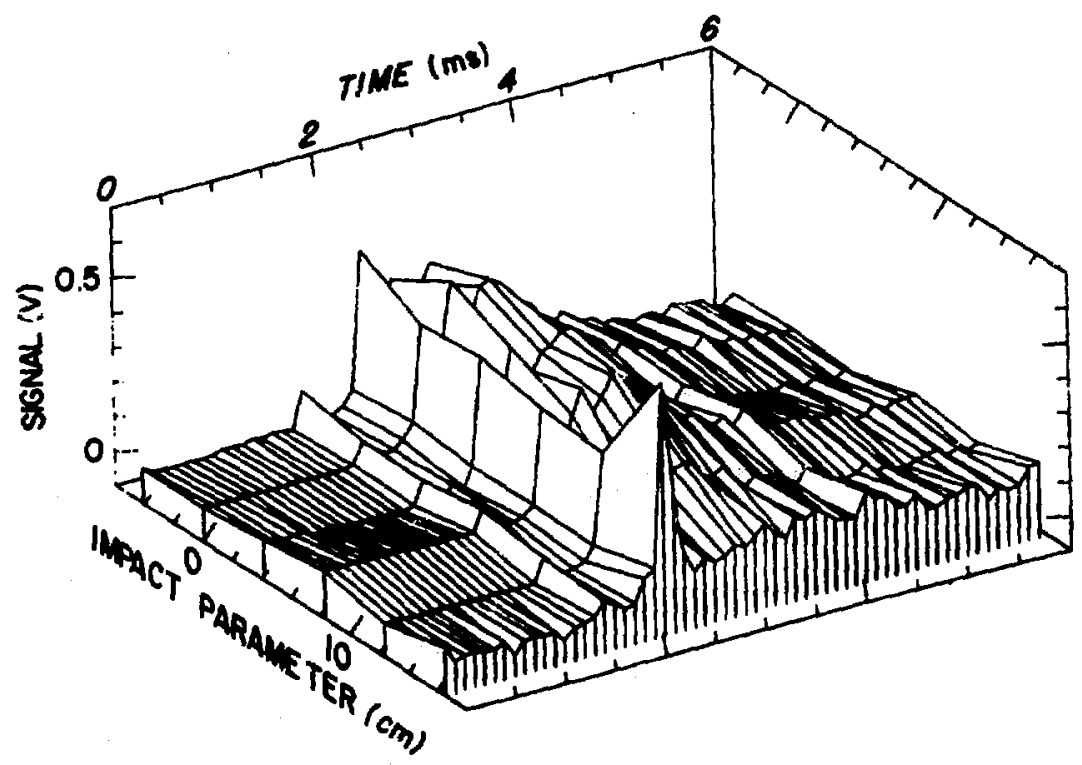

F18. 21.

CV profiles at 1.5-me risetime showing a pronounced wall hit at approximately 2 ase during formation. Current starts at $1.5 \mathrm{~ms}$. 
Because aeries of closely spaced (unresolvable with the MCSS system) Cr, N1I, NIII, PeI, and FeII ${ }^{7}$ lines exist within $\pm 1.0 \mathrm{~nm}$ of the $C V(227.1 \mathrm{~nm})$ 11ne, the radiation is assumed to cone from these lines (N1, Fe, and Cr are the constituents of the vacuun vesse1), especially from the NiI 11 ne at $227.2 \mathrm{~nm}$. Similar lines exist near the $D_{B}$ line but in much wore 11mited quantity, and no such bursts of radiation are observed near $D_{B}$, effectively ruling out the possibility of recombination radiation from $\mathrm{D}^{+}$and inpurity lons being the cause.

Also observed in recent discharges (with all risetimes) is assive flux of radiation in the outer chords beginning at 2-3 ms into the discharge, as shown in F1g. 22. This late time radiation also hạs no wavelength structure near the CV IIne and 18 not observed near other lines studied. This again suggests metal line radiation from a wall interaction phenosena, perhaps Indicative of a monotonic 1088 of toroldal equilibrium, 8 such as wight be expected as the 2-cm aluminum shell gradually disappears during a discharge. The 108 of the positioning vertical field due to the shell disappearing would

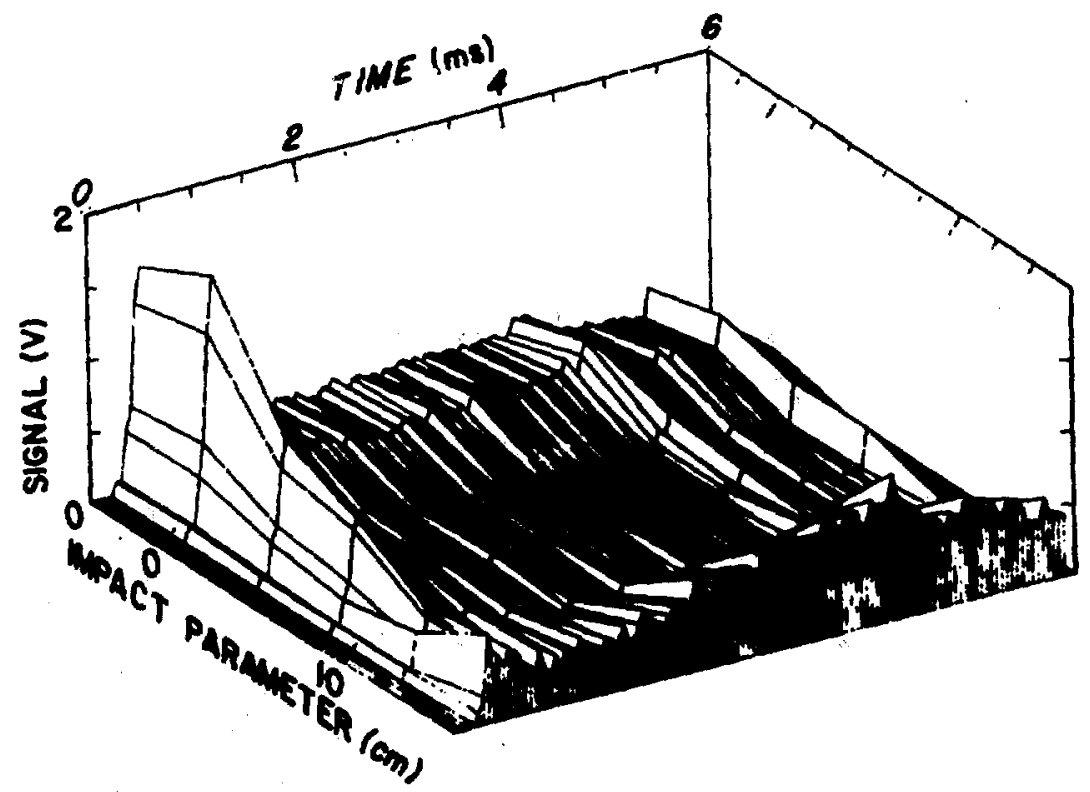

F18. 22 .

CV profiles at 0.25 -ns rise showing the rapid burnout of the ilne followed by a pronounced late tive ( $>3 \mathrm{~ms})$ wall interaction seen by the outer chords. Current starte at 0.25 ms. 
lead one to expect that the plasma colunn would lean on the outside wall late in the discharge, resulting in bolling impurities off the wall and linters. The observed radiation is consistent with such a picture (indeed, preliminary results with externally applied vertical field qualitatively alter the time history of this radiation), * although by no means is this the only possible explanation. This explanation does not account for the historical change in this effect ince the shell has always had a 2-3-ms time constant. Presumably wall conditioning explains the historical differences. It should be noted that this refluxing in the outer chord 18 most pronounced for the 0.25 -ms risetime discharges. The more subdued nature of this refluxing observed for the longer riset Imes may simply be Indicative of a shorter wall-scrubbing time because of the increased length of time necessary to get the column hot. Those discharges last no longer than the faster risetime discharges, so the total wall interaction time for a hot plasma 18 reduced at longer risetime.

\section{v. CONCLUSIONS}

The result of these measurements is to provide a characterization for ZT-40M operation rather than to provide any remarkable new physics enlightenment. As a result of these measurements, a number of statements can be made concerning ZT-40M plasmas.

(1) The bulk plasma behavior is dependent on current level and current risetine predominantly in terms of timescales, 1.e., how long it takes to achleve a hot plasma, rather than in any discernible changes in radial structure during setup or decay phases.

(2) The setup phase of the discharge goes sequentially through all the Interwediate oxygen Impurity radial structures one would expect to observe, 1.e., no anomalous tadial heating structures (for instance an annular theral instability) ${ }^{9}$ seen to exist.

(3) The carbon enisetion peaks at a tiae during the discharge that is consistent with a startup picture (after OVI burnthrough) in which the energy confinewent tive $\tau_{E}$ is much longer than the energy input time scale. This results in energy losses that are much lower than the energy Input (at least up until CV begins to burn through).

\footnotetext{
"Informetion supplied by R. S. Massey, Los Alamos National Laboratory.
} 
(4) The operating window, defined by the ability to burn through the oxygen 1mpurities and begin emitting CV radiation, appears to shift its peak upward in prossure with increasing risetine.

(5) Considerable evidence of wail Interaction is observed and the time of occurrence of this low-lying metal radiation is in agreenent with the basic equilibrium loss time for the aluminum she11.

This last point will be one focus of an upcoming set of experinents which will address the question of vertical fleld and equilibrium configuration in ZT-40M.

\section{REFERENCES}

1. D. A. Baker, C. J. Buchenauer, L. C. Burkhardt, J. N. D1Marco, J. N. Downing, A. Haberstich, R. B. Howell, J. C. Ingraham, A. R. Jacobson, K. A. Klare, E. M. Little, R. S. Massey, G. Miller, J. A. Phillips, A. E. Schofield, K. F. Schoenberg, K. S. Thomas, R. G. Watt, P. G. Weber and R. Wilkins, "Inttial Reversed-Field P1nch Experiments on ZT-40M W1th A Metallic Vacuum Liner," submitted to 10th European Conference on Controlled Fuston and Plasma Phystcs, September 14-19, 1981, Moscow, Los Alawos National Laboratory report LA-UR-81-1413 (May 1981).

2. R. G. Watt, "A Spatially Resolved Spectrometer system for the ZT-40 Device," Los Alamos National Laboratory report LA-8823-MS (May 1981).

3. A. Haberstich and K. A. Klare, "Single-Polnt Thomson Scattering Measurements on ZT-40M," Bul1. Am. Phys. Soc. 26, 1041 (1981).

4. K. B. Freese, R. S. Massey, Rita Gribble and J. D. Smith, Multiple-Point Thomson Scattering Measurement for the $2 T-40$ Reversed-Field P1nch," Proc. Los Alamos Conf. on Opt1c8, SPIE 288, 1981.

5. A. R. Jacobson and L. J. Jolln, "E1ght-Chord $\mathrm{CO}_{2}$ Interferometer for Plasma Density Measurements on ZT-40," Proc. Los Alamos Optics Conf., Paper B211 (1981).

6. Lochte-Holtgreven, Plasma Dlagnost1c8 (North-Holland Publishing Company, Ans terdan, 1968).

7. Striganov and Svontitsk11, Tables of Spectral Lines of Neutral and Ionized Atoms (P1enun Data Corporation, New York, 1968).

8. V. S. Mukhovatov and V. D. Shafranov, "Plasma Equ1librium In a Tokanak," Nucl. Fusion 11, 605 (1971).

9. E. J. Caranana and F. W. Perkins, "The Role of Inpurttles In Producing Thermal Instability in Ohaically Heated P1asma," Nucl. Fusion 21, 93 (1981). 